\title{
False echocardiographic diagnosis of aortic root dissection in case of abdominal aortic dissection
}

\author{
M KOLETTIS, P TOUTOUZAS, D AVGOUSTAKIS
}

From the Department of Cardiology of the University of Athens, and the Cardiac Department, the 7th Hospital, The Institute of Social Security, Athens, Greece

SUMMARY A patient with strong clinical and radiological indications of dissection involving the ascending aorta had this "confirmed" on an echocardiogram which showed a typical pattern of double lumen. At necropsy there was dissection of the abdominal aorta but the heavily calcified thoracic aorta was free of dissection.

Echocardiography may be useful but not entirely reliable in the diagnosis of dissection even in the presence of a typical clinical picture.

Echocardiography has been reported to be successful in the diagnosis of aortic dissection involving the aortic root. ${ }^{1-4}$

In this report a case is presented in which an echocardiographic pattern strongly suggestive of aortic root dissection proved to be false, despite the actual presence of dissection of the abdominal aorta and the strong clinical and radiological indications of dissection involving the ascending aorta.

\section{Case report}

The 95-year-old woman was admitted because of left lateral chest pain of several hours' duration. She was known to have moderate hypertension for the last 20 years which was incompletely controlled with small and irregular doses of frusemide and reserpine.

On admission, her blood pressure was $150 / 90$ $\mathrm{mmHg}$ in both arms, the heart was irregular, and a grade $2 / 6$ early diastolic murmur was heard at the second right interspace and along the right and left sternal borders. The electrocardiogram showed atrial fibrillation, right bundle-branch block, and ST-T changes compatible with ischaemia. The laboratory examinations were noncontributory.

During the next three days the patient was confused, the temperature rose to $38^{\circ} \mathrm{C}$, and, in spite of several recurrences of the chest pain, the electrocardiogram and the laboratory findings showed no appreciable change. With the above

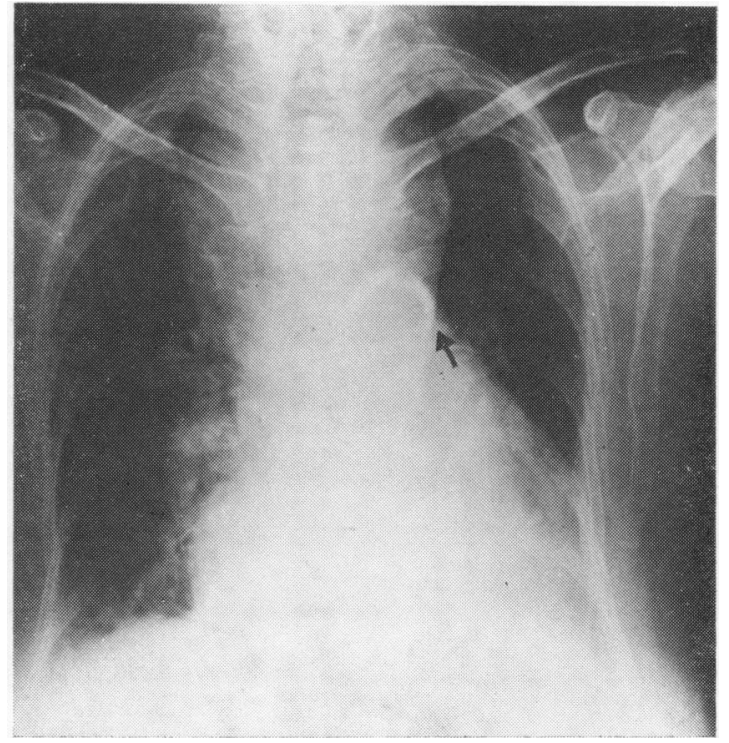

Fig. 1 Chest $\mathrm{x}$-ray film. There is a large shadow overlying the calcified aortic arch (indicated by the arrow). The additional shadow is more translucent than the true aortic shadow which is defined by the calcified aortic wall.

findings the diagnosis of aortic dissection involving the ascending aorta was considered.

A chest $x$-ray film (Fig. 1) showed a round shadow overlying the calcified aortic arch, and this was thought to confirm the clinical impression of dissection, with the calcified wall representing 
the wall of the true lumen and the additional shadow representing the false lumen.

Accordingly, the patient was put on an antihypertensive and anticontractile regimen with prazosin $6 \mathrm{mg}$ daily and oxprenolol $160 \mathrm{mg}$ daily. With this treatment the blood pressure decreased to 100 to $120 / 70$ to $80 \mathrm{mmHg}$ and the patient stabilised.

During the fifth day in hospital, there was a temporary increase in the blood pressure to $160 / 90 \mathrm{mmHg}$ and the patient felt pain in the abdomen and the following morning the right leg was pale, cold, and sore and the femoral pulse was not palpable. The next morning, however, the femoral pulse reappeared and the colour and temperature of the leg were normal. These findings were interpreted as meaning extension of the dissection to the abdominal aorta and the right iliac artery and the subsequent creation of re-entry.

With the addition of reserpine $0.1 \mathrm{mg}$ and frusemide $20 \mathrm{mg}$ daily, the blood pressure fell to 100 to $110 / 70$ to $80 \mathrm{mmHg}$ and the condition stabilised again.

At this time an echocardiogram was made, using a Unirad Sonograph type II echocardiograph with a transducer of $13 \mathrm{~mm}$ diameter and $2.25 \mathrm{MHz}$ frequency response. The recordings were made on a sensitive tape paper at a speed of $50 \mathrm{~mm} / \mathrm{s}$, with Honeywell apparatus.

The echocardiogram (Fig. 2) showed the width of the aortic root at the upper normal limits $(37 \mathrm{~mm})$ but greatly increased thickness of the anterior wall $(19 \mathrm{~mm})$, with its inner and outer margins separated by a space, with a few scattered echoes, and maintaining a parallel movement. The aortic valve leaflets were clearly seen without thickening or calcification and during their opening they did not extend beyond the inner surface of the anterior and posterior aortic walls. The findings were interpreted as indicating the presence of false lumen of the anterior wall of the ascending aorta and confirming the clinical diagnosis.

Four days later the patient was struck by severe abdominal pain followed by bloody stools, fell into shock, and the next morning died. Necropsy proved the existence of dissection of the posterior wall of the abdominal aorta, extending to both common iliac arteries. The intimal tear was localised at the upper part of the abdominal aorta and there was no external rupture. The thoracic aorta showed heavy thickening and calcification but was free of dissection.

At the upper mediastinum there was a voluminous retrosternal goitre which was evidently the cause of the shadow giving the $x$-ray picture of aortic dissection.

\section{Discussion}

Millward et al. ${ }^{1}$ reported in 1972 the echocardiographic diagnosis of dissecting aneurysm of the ascending aorta, documented by distinct widening of the aortic root and the presence of four instead of two parallel echoes, delineating the false lumen of the anterior and posterior aortic walls. The following year Nanda et al. ${ }^{2}$ reported on the echocardiographic diagnosis of six cases of aortic dissection establishing three main diagnostic criteria: (1) enlargement of the aortic root $(42 \mathrm{~mm}$ or more), (2) thickening of the anterior (16 to 21 $\mathrm{mm}$ ) and/or the posterior wall (10 to $13 \mathrm{~mm}$ ), and (3) maintenance of parallelism between the inner

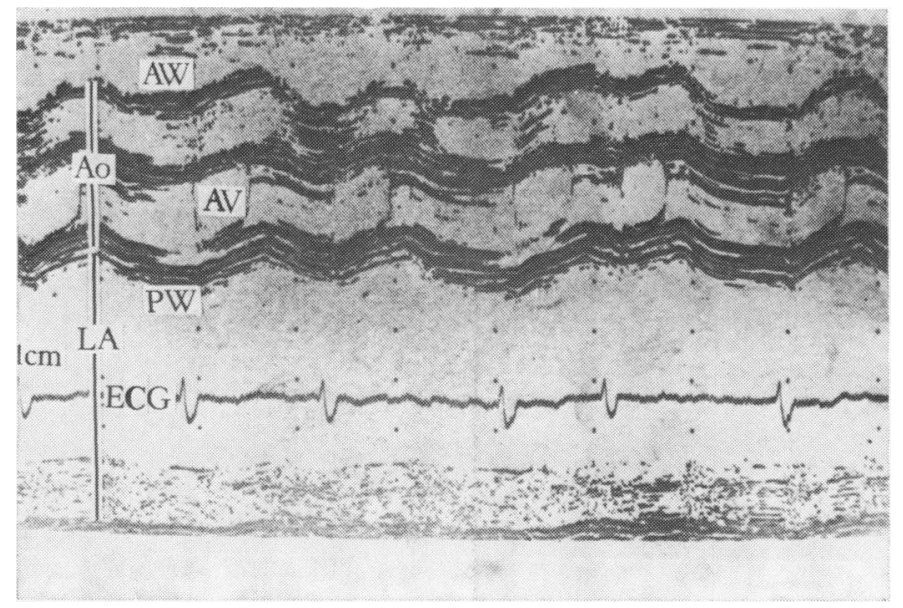

Fig. 2 Echocardiogram of the aortic root. The width of the aortic root $(37 \mathrm{~mm})$ is not increased but there is distinct widening of the anterior wall $(19 \mathrm{~mm})$. Its inner and outer margins are separated by a space containing a few scattered echoes, and maintain a parallel movement. The aortic valve leaflets are free of thickening or calcification and they do not extend beyond the inner margins of the anterior and posterior wall. Explanation of abbreviations: $A W$, arterior aortic wall; Ao, aorta; $A V$, aortic valve; $P W$, posterior aortic wall; $L A$, left atrium; ECG, electrocardiogram. 
and outer margins of the separated walls. It is important to document the aortic leaflets with little or no thickening or calcification showing normal motion not extending beyond the margins of the inner lumen. Calcification of the valve may produce multilayered echoes, which may give an erroneous appearance of widening of the aortic walls and the presence of a false lumen. The above criteria have been confirmed later by others. ${ }^{3-5}$

In simple dilatation of the aorta enlargement of the aortic root, increased wall thickness, ${ }^{34}$ and parallel movement ${ }^{4}$ may be present. The increased thickness to the limits indicative of dissection, that is $16 \mathrm{~mm}$ or more, however, never affected the anterior wall in the cases of Brown et al. ${ }^{4}$ and never assumed the pattern of double lumen in the cases of Moothart et al. ${ }^{3}$ which, if present, was diagnostic of dissection.

In our case, though the width of the aorta was less than $42 \mathrm{~mm}$, there was thickening of the anterior wall of $19 \mathrm{~mm}$ with a typical pattern of double lumen and parallel movement of the separated margins. Moreover, the aortic valve leaflets were free of thickening or calcification and they did not extend beyond the inner margins of the anterior and posterior walls. However, even more important is that the echocardiographic pattern proved to be false despite the actual presence of dissection of the abdominal aorta and strong clinical and radiological indications of involvement of the ascending aorta, which should make the echocardiographic diagnosis readily acceptable, as suggested also by Brown et al. ${ }^{4}$
The cause of the echocardiographic pattern of false lumen in our case is most likely the reflection of multilayered echoes from the thickened and calcified wall of the ascending aorta, as happened also in the case of Krueger et al. ${ }^{6}$

Our case indicates that the echocardiographic pattern of dissection cannot be entirely reliable even in the presence of a "typical" clinical picture.

\section{References}

1 Millward DK, Robinson NJ, Craige E. Dissecting aortic aneurysm diagnosed by echocardiography in a patient with rupture of the aneurysm into the right atrium. Am f Cardiol 1972; 30: 427-31.

2 Nanda NC, Gramiak R, Shah DM. Diagnosis of aortic root dissection by echocardiography. Circulation 1973; 48: 506-13.

3 Moothart RW, Spangler RD, Blount SG Jr. Echocardiography in aortic root dissection and dilatation. Am $\mathcal{F}$ Cardiol 1975; 36: 11-6.

4 Brown OR, Popp RL, Kloster FE. Echocardiographic criteria for aortic root dissection. Am f Cardiol 1975; 36: 17-20.

5 Yuste P, Aza V, Minguez I, Cerezo L, MartinezBordiu C. Dissecting aortic aneurysm diagnosed by echocardiography. A pre- and post-operative study. Br Heart f 1974; 36: 111-3.

6 Krueger SK, Starke H, Forker AD, Eliot RS. Echocardiographic mimics of aortic root dissection. Chest 1975; 67: 441-4.

Requests for reprints to Dr Miltiades Kolettis, The Cardiac Department, The 7th Hospital, The Institute of Social Security, 11 Kaftatzoglou Street, Athens 906, Greece. 